\title{
Ureteroneocystostomy in primary vesicoureteral reflux: critical retrospective analysis of factors affecting the postoperative urinary tract infection rates
}

\author{
Hasan Serkan Dogan, Ali Cansu Bozaci, Burhan Ozdemir, Senol Tonyali, Serdar Tekgul \\ Department of Urology, Hacettepe University Faculty of Medicine, Ankara, Turkey
}

\section{ABSTRACT}

Introduction: To determine the parameters affecting the outcome of ureteroneocystostomy (UNC) procedure for vesicoureteral reflux (VUR).

Materials and Methods: Data of 398 patients who underwent UNC procedure from 2001 to 2012 were analyzed retrospectively. Different UNC techniques were used according to laterality of reflux and ureteral orifice configuration. Effects of several parameters on outcome were examined. Disappearance of reflux on control VCUG or absence of any kind of UTI/symptoms in patients without control VCUG was considered as clinical improvement.

Results: Mean age at operation was $59.2 \pm 39.8$ months and follow-up was $25.6 \pm 23.3$ months. Grade of VUR was 1-2, 3 and 4-5 in 17, 79, 302 patients, respectively. Male to female ratio was 163/235. UNC was performed bilaterally in 235 patients and intravesical approach was used in 373 patients. The frequency of voiding dysfunction, scar on preoperative DMSA, breakthrough infection and previous surgery was $28.4 \%, 70.7 \%$, $49.3 \%$ and $22.4 \%$, respectively. Twelve patients (8.9\%) with postoperative contralateral reflux were excluded from the analysis. Overall clinical improvement rate for UNC was 92\%. Gender, age at diagnosis and operation, laterality and grade of reflux, mode of presentation, breakthrough infections (BTI) under antibiotic prophylaxis, presence of voiding dysfunction and renal scar, and operation technique did not affect the surgical outcome. However, the clinical improvement rate was lower in patients with a history of previous endoscopic intervention (83.9\% vs. 94\%). Postoperative UTI rate was 27.2\% and factors affecting the occurrence of postoperative UTI were previous failed endoscopic injection on univariate analysis and gender, preoperative BTI, postoperative VUR state, voiding dysfunction on multivariate analysis. Surgery related complication rate was $2 \%$ (8/398). These were all low grade complications (blood transfusion in 1, hematoma under incision in 3 and prolonged hospitalization secondary to UTI in 4 patients). In long term, 12 patients are under nephrologic follow-up because of hypertension in 5 , increased serum creatinine in 5, proteinuria in 1 and hematuria in 1 patient and all these patients had preoperative scarred kidneys.

Conclusions: Despite its invasive nature, UNC has a very high success rate with a negligible percent of complications. In our cohort, the only factor that negatively affected the clinical improvement rate was the history of previous antireflux interventions where the predictive factors for postoperative UTI were previous failed endoscopic injection, female gender, preoperative BTI, persistent VUR and voiding dysfunction.

\section{ARTICLE INFO}

Key words:

Vesico-Ureteral Reflux;

Urinary Tract Infections; Kidney

Diseases; Child

Int Braz J Urol. 2014; 40: 539-45

Submitted for publication:

July 30,2013

Accepted after revision:

January 22, 2014 


\section{INTRODUCTION}

Vesicoureteral reflux is one of the most important causes of nephropathy in children. Although there are lots of studies with conflicting conclusions on the management of this disease, which are probably depending on the study designs and population, the present data recommend us to consider VUR as an important disease particularly in a selected group of high risk patients who are defined as symptomatic male or female patients after toilet-training with high grade reflux (grades IV-V), abnormal kidneys and with/without lower urinary tract dysfunction (1). Interventions to prevent reflux, most of the time, are not the first step option, however indicated in patients with recurrent febrile urinary tract infections under antibiotic prophylaxis, whose chance of spontaneous resolution is unlikely, whose kidneys are scarred and with parental decision (2). Amongst these interventions, open surgery has an important role with high success and low complication rates despite being more invasive when compared to endoscopic techniques. The present study aims to investigate the factors affecting the surgical outcomes of open ureteral reimplantation techniques in a considerably large population within a time period of more than 10 years.

\section{MATERIALS AND METHODS}

The data of patients who underwent ureteroneocystostomy (UNC) from 2001 to 2012 for treatment of vesicoureteral reflux (VUR) were reviewed retrospectively. Patients with history of previous open antireflux surgery, secondary VUR due to posterior urethral valve and overt spinal dysraphism were excluded. Among more than 500 cases, the data of 398 patients were available and recorded to a standard sheet. Different UNC techniques (Cohen UNC in 367, Glenn-Anderson in 6, Lich-Gregoir in 25 cases) were used according to laterality of reflux and ureteral orifice configuration. Because of the deficiency of postoperative control VCUG in some of our patients, we preferred to use the "clinical improvement' term instead of 'success'. Disappearance of reflux on control voiding cystourethrography (VCUG, 254 patients) or absence of any kind of urinary tract infection (UTI) and/or symptoms in patients without control VCUG was considered as clinical improvement. Voiding dysfunction was defined as the presence of lower urinary tract symptoms (presence of urge, incontinence, weak stream, hesitancy, frequency and urinary tract infections, but without overt uropathy or neuropathy) in children older than 5 years in association with or without abnormal symptom score (3) or urodynamic study. Effects of several parameters on outcome were examined. SPSS 15.0 software program was used to perform statistical analysis. Mann-Whitney test, chi-square test, T-test were used in where appropriate and a $p$ value $<0.05$ was used for determination of statistical significance.

\section{RESULTS}

Patient characteristics are given in Table-1. Twelve patients (8.9\%) amongst unilateral cases with

Table 1 - Patient characteristics.

\begin{tabular}{|c|c|}
\hline $\begin{array}{l}\text { Mean age at diagnosis / } \\
\text { operation (month) }\end{array}$ & $47.7 \pm 41.8 / 59.2 \pm 39.8$ \\
\hline Gender (male/female) & $163 / 235$ \\
\hline Reflux grade (1-2 / 3 / 4-5) & $17 / 79 / 301$ \\
\hline Unilateral / bilateral & $135 / 263$ \\
\hline $\begin{array}{l}\text { UNC: Intravesical / } \\
\text { extravesical / tailoring }\end{array}$ & $373 / 25 / 16$ \\
\hline Voiding dysfunction (+) & $28.4 \%$ \\
\hline Scar on nephrogram (+) & $70.7 \%$ \\
\hline Breakthrough infection (+) & $49.3 \%$ \\
\hline Previous endoscopic injection (+) & $22.4 \%$ \\
\hline Mean hospitalization period (days) & $4 \pm 2$ \\
\hline Follow-up (months) & $25.6 \pm 23.3$ \\
\hline Clinical improvement rate & $92 \%$ \\
\hline $\begin{array}{l}\text { Contralateral reflux / } \\
\text { Unilateral UNC }\end{array}$ & $12 / 135$ \\
\hline Postoperative UTI & $27.2 \%$ \\
\hline
\end{tabular}


postoperative contralateral reflux were excluded from the analysis for surgical outcome evaluation. Overall clinical improvement rate for UNC was 92\%. Gender, age at diagnosis and operation, laterality and grade of reflux, mode of presentation, breakthrough infections (BTI), presence of voiding dysfunction ( $>5$ years old), presence of renal scar and operation technique did not affect the surgical outcome (Table-2). However, the clinical improvement rate was lower in patients with a history of previous endoscopic injection (83.9\% vs. 94\%, $p=0.002$, chi-square test). Number of previous injections (1 versus more than 1 ) did not affect the clinical improvement rates (87.8\% vs. $80.8 \%$, chi-square test, $p=0.406$ ).

Within the postoperative follow-up period, UTI was present in $27.2 \%$ of all patients. The distribution of postoperative UTI was indifferent regarding laterality and severity of VUR, the presence of scar, operation type and age were similar in patients with and without postoperative UTI (Table-2). Postoperative UTI was more likely in patients with persistent VUR following UNC (22.1\% vs. $89.7 \%$, chi-square, $p<0.001$ ), in females, in patients with preoperative BTI, with previous failed endoscopic injection and with voiding dysfunction (Table-2). Multivariate analysis (binary logistic regression analysis) revealed gender, preoperative BTI, operative success and voiding dysfunction as significant predictive factors.

Surgery related complication rate was $2 \%$ (8/398). These were all low grade complications (blood transfusion in 1, hematoma under incision in 3 and prolonged hospitalization secondary to UTI in 4 patients). In long term, 12 patients are under nephrologic follow-up because of hypertension in 5 , increased serum creatinine in 5 , proteinuria in 1 and hematuria in 1 patient. All these 12 patients preoperatively had bilateral high grade VUR with significant renal scarring.

\section{DISCUSSION}

VUR is still an important and the most frequent etiological factor for chronic renal failure in Turkey (4). Although many authors describe VUR as a benign disease (5), the consequences may be significant (6). Therefore, it should be investigated and followed up with great caution when detected.

The contemporary approach to VUR disease is mostly conservative since most of the cases have a considerable chance of spontaneous resolution. Cases who have less chance or failed to resolve under conservative treatment become the candidates for interventional management. Today, endoscopic approach constitutes primary treatment choice in most of the patients. UNC is mostly indicated in cases who have a previous endoscopic injection failure, high grade VUR, VUR in combination with ureterovesical obstruction, significant bladder pathologies (diverticula, ureterocele, ectopic ureter, duplex system), regarding the parental decision and relatively in patients with bladder dysfunction (2). There are several open UNC techniques those all aim the creation of a sufficient length of submucosal tunnel without any torsion or kinking. All of these UNC techniques have individual advantages and disadvantages with similar success rates (7).

The presented series aim to gather an experience of more than 10 years. Although the number of cases within this time period was more than 500 , because of the retrospective nature of the study we included only the cases with sufficient data for statistical analysis. The patient characteristics revealed that $60 \%$ of the patients were female, $66 \%$ had bilateral disease, 70\% had scarred kidneys and more than $20 \%$ had history of previous endoscopic injection. These figures are in accordance with the literature and indications for open surgery (8).

Since its introduction, intravesical cross-trigonal Cohen's reimplantation technique became popular (9). This technique enables to perform synchronous bilateral UNC as well as providing the correction of bladder pathologies. The only disadvantage of potential difficulty in retrograde catheterization for future interventions for stone disease is today overcome by invention of the flexible instruments. The dominancy of intravesical approach in our series depends on these mentioned facts, the preponderance of bilateral cases and surgeon's preference. For unilateral cases, Lich-Gregoir technique can be the option. However, the surgical success rates didn't differ regarding the surgical technique. 
Table 2 - Analysis of the parameters which can affect the outcome (a: chi-square test, $b$ : Mann-Whitney test).

\begin{tabular}{|c|c|c|c|c|c|}
\hline Parameter & & $\begin{array}{c}\text { Clinical } \\
\text { improvement (\%) }\end{array}$ & $p^{a}$ & $\begin{array}{c}\text { Postoperativ } \\
(\%)\end{array}$ & $p^{a}$ \\
\hline \multirow[t]{3}{*}{ Gender } & Male & 94.2 & \multirow{3}{*}{0.129} & 11.7 & \multirow{3}{*}{$<0.001$} \\
\hline & & & & & \\
\hline & Female & 89.9 & & 38.1 & \\
\hline \multirow[t]{2}{*}{ Laterality } & Unilateral & 89.3 & \multirow{2}{*}{0.266} & 25.4 & \multirow{2}{*}{0.544} \\
\hline & Bilateral & 92.7 & & 28.3 & \\
\hline \multirow[t]{3}{*}{ Grade of reflux } & $1-2$ & 91.2 & & 25 & \\
\hline & 3 & 91.3 & \multirow[t]{2}{*}{0.402} & 32.5 & \multirow[t]{2}{*}{0.529} \\
\hline & $4-5$ & 92.7 & & 26.1 & \\
\hline \multirow[t]{3}{*}{ Voiding dysfunction } & Yes & 94.7 & \multirow{3}{*}{1.000} & 50 & \multirow{3}{*}{$<0.001$} \\
\hline & & & & & \\
\hline & No & 94.3 & & 15.5 & \\
\hline \multirow[t]{2}{*}{ Renal scarring } & Yes & 91.4 & \multirow[b]{2}{*}{0.519} & 28.7 & \multirow[b]{2}{*}{0.120} \\
\hline & No & 93.4 & & 20.8 & \\
\hline \multirow[t]{2}{*}{ Preoperative BTI } & Yes & 90.1 & \multirow[b]{2}{*}{0.088} & 39.2 & \multirow[b]{2}{*}{$<0.001$} \\
\hline & No & 94.9 & & 16.9 & \\
\hline \multirow[t]{3}{*}{ Number of preoperative BTI } & 0 & 94.9 & & 16.9 & \multirow{3}{*}{$<0.001$} \\
\hline & 1 & 89.7 & \multirow[t]{2}{*}{0.227} & 37.3 & \\
\hline & $>1$ & 90.6 & & 40.2 & \\
\hline \multirow{3}{*}{$\begin{array}{l}\text { Preoperative history of subureteral } \\
\text { injection }\end{array}$} & Yes & 83.9 & \multirow{3}{*}{0.002} & 39.3 & \multirow{3}{*}{0.006} \\
\hline & & & & & \\
\hline & No & 94 & & 24 & \\
\hline \multirow[t]{4}{*}{ Operative approach } & Intravesical & 92.7 & \multirow[b]{2}{*}{0.704} & 26.7 & \multirow[b]{2}{*}{0.250} \\
\hline & Extravesical & 91.9 & & 37.5 & \\
\hline & \multicolumn{2}{|c|}{ Clinical improvement } & & \multicolumn{2}{|c|}{ Postoperative UTI } \\
\hline & Yes & No & & No & Yes \\
\hline Age at diagnosis (months) & $49.2 \pm 41.8$ & $41.9 \pm 43.1$ & & $48.5 \pm 42.4$ & $48.7 \pm 42.1$ \\
\hline$p^{b}$ & \multicolumn{2}{|c|}{0.246} & & \multicolumn{2}{|c|}{0.801} \\
\hline Age at operation (months) & $60.8 \pm 40.3$ & $47.3 \pm 35.2$ & & $60 \pm 40.2$ & $59.3 \pm 40.2$ \\
\hline$p^{b}$ & & & & & \\
\hline
\end{tabular}


Unlike the endoscopic injection techniques (10), success of open UNC does not seem to be affected by the grade of reflux or the presence of voiding dysfunction $(8,11,12)$. Similarly, our results revealed that UNC had a constant success rate regardless of the grade of VUR, presence of voiding dysfunction and also was not affected by the number of the preoperative breakthrough infections, presence of renal scar or the age of the patient. This might be attributed to the correction of the anatomic defect by the creation of a submucosal tunnel with an adequate length which prevents the retrograde urine reflux. Hence, parents who consider the success of the procedure prefer open surgery (13). One advantage of UNC over endoscopic approach is the durability of the success rates. Long term results of endoscopic technique yielded a reflux recurrence rate of about 25\% (1417). However, in patients who underwent a successful UNC, recurrence is an extremely rare event and persistent vesicoureteral reflux after reimplantation resolves spontaneously in most children and can be managed non-operatively with good long-term outcomes (8). Therefore, current practice is not to perform routine postoperative VCUG. However, some authors recommend VCUG for patients with hydronephrosis, renal scarring, UNC with tailoring (18), voiding dysfunction (19) and high grade VUR (20). Our policy is not to recommend routine postoperative VCUG and reserve it for patients with sustaining hydronephrosis, recurrent UTI or complex cases.

The single discrepancy of our findings from the literature was the worse clinical outcome of UNC in patients who had a history of previous injection. It was previously stated that UNC had a very high success also in patients who had an injection failure $(11,21,22)$. Considering the fact that even though not all of our patients had a control VCUG, our results showed that patients with a history of previous failed endoscopic injection had a significantly lower clinical improvement rate (83.9\% vs. 94\%). Several analyzes including all mentioned parameters (gender, age at diagnosis and operation, laterality and grade of reflux, mode of presentation, breakthrough infections, presence of voiding dysfunction and renal scar, operation technique) have been done. The only difference between patients with and without history of failed previous injection was the age of the patient at operation. Patients with previous failed injection treatment were older $(69.6 \pm 45.2$ vs. $56.1 \pm 37.6$ months, Mann-Whitney test, $p=0.030$ ) and this may simply be attributed to the time delay from the injection date to the decision date to perform open UNC.

Despite the expectations of parents, the primary aim of anti-reflux interventions is to prevent the retrograde reflux of urine and infection -if present- to kidney rather than sterilizing the bladder urine. Actually, the postoperative UTI is not an infrequent event. Postoperative UTI is reported between 20 to 50\% of cases (23-27). In these studies, preoperative grade of reflux, presence of dysfunctional elimination syndrome, presence of renal scar and preoperative BTI were found as causative factors. The rate of postoperative UTI was $27.2 \%$ and factors affecting the occurrence of postoperative UTI in our series were previous failed endoscopic injection on univariate analysis and female gender, preoperative BTI, operative success, voiding dysfunction on multivariate analysis.

Although it is considered as the most invasive treatment method amongst the anti-reflux interventions, UNC has very few postoperative complication rates. The surgery related complication rate and contralateral reflux development in our series were 2\% and 8.9\% respectively, which were consistent with the literature (2,28-30). Complications were as follows: bleeding required blood transfusion in 1 patient, hematoma under incision in 3 and prolonged hospitalization secondary to UTI in 4 patients. These complications were all low grades and managed conservatively. There is an increasing effort to minimize the invasiveness of this open surgery. Apart from the laparoscopic technique, contemporary series report open UNC without or with 1-day catheter technique, or via inguinal incision, or bilateral extravesical with minimal ureteral dissection with no postoperative urinary retention $(28,29,31,32)$.

VUR is most of the times considered as a benign entity. Besides this, it can be a serious problem in a group of patients particularly with bilateral involvement in association with significant scarring. This group of patients is under signifi- 
cant risk of hypertension and renal insufficiency $(33,34)$. VUR is the leading cause of end-stage renal disease in children which varies between 5-25\% of cases (35-37). With great interest of UTI management, the incidence of VUR nephropathy has decreased significantly $(38,39)$. Because of the study designs and retrospective nature of the studies, it is difficult to have an exact rate of VUR-related nephrologic sequelas (hypertension, proteinuria, chronic renal insufficiency) (40). In our series of operated VUR disease, nephrologic follow-up was required in 3\% of patients. The causes of nephrologic follow-up were hypertension in 5, increased serum creatinine in 5, proteinuria in 1 and hematuria in 1 patient. The development of nephrologic problems was not associated with the success of the operation that only 1 of this 12 patients had a surgical failure after UNC which was a similar distribution when compared with the patients without nephrologic complications. Therefore, surgical success does not rule out development of nephrologic long term complications and uronephrologic follow up should be continued after the operation particularly for patients with bilateral high grade VUR and renal scarring preoperatively.

\section{CONCLUSIONS}

UNC is the most effective method of preventing VUR. It has high success and low complication rates. The only factor affecting the clinical improvement rate is the history of previous endoscopic injection failure. Postoperative UTI may occur despite a successful operation. Previous failed endoscopic injection on univariate analysis and gender, preoperative BTI, operative success, voiding dysfunction on multivariate analysis were detected as the factors affecting the occurrence of postoperative UTI. Although it has a benign prognosis in most of the patients, bilateral high grade VUR with renal scarring may have important consequences and long term uronephrologic follow-up should be recommended.

\section{CONFLICT OF INTEREST}

None declared.

\section{REFERENCES}

1. Tekgül S, Riedmiller H, Hoebeke P, Kočvara R, Nijman RJ, Radmayr $\mathrm{C}$, et al.: EAU guidelines on vesicoureteral reflux in children. Eur Urol. 2012; 62: 534-42.

2. Sung J, Skoog S: Surgical management of vesicoureteral reflux in children. Pediatr Nephrol. 2012; 27: 551-61.

3. Akbal C, Genc Y, Burgu B, Ozden E, Tekgul S: Dysfunctional voiding and incontinence scoring system: quantitative evaluation of incontinence symptoms in pediatric population. J Urol. 2005; 173: 969-73.

4. Bek K, Akman S, Bilge I, Topaloğlu R, Calişkan S, Peru H, et al.: Chronic kidney disease in children in Turkey. Pediatr Nephrol. 2009; 24: 797-806. Erratum in: Pediatr Nephrol. 2009; 24: 881.

5. Venhola M, Uhari M: Vesicoureteral reflux, a benign condition. Pediatr Nephrol. 2009; 24: 223-6.

6. Coulthard MG: Vesicoureteric reflux is not a benign condition. Pediatr Nephrol. 2009; 24: 227-32.

7. Duckett JW, Walker RD, Weiss R: Surgical results: International Reflux Study in Children--United States branch. J Urol. 1992; 148: 1674-5.

8. Hubert KC, Kokorowski PJ, Huang L, Prasad MM, Rosoklija I, Retik $A B$, et al.: Clinical outcomes and long-term resolution in patients with persistent vesicoureteral reflux after open ureteral reimplantation. J Urol. 2012; 188: 1474-9.

9. Cohen MH, Rotner MB: A new method to create a submucosal ureteral tunnel. J Urol. 1969; 102: 567-8.

10. Elder JS, Diaz M, Caldamone AA, Cendron M, Greenfield S, Hurwitz $\mathrm{R}$, et al.: Endoscopic therapy for vesicoureteral reflux: a meta-analysis. I. Reflux resolution and urinary tract infection. J Urol. 2006; 175: 716-22.

11. Granata C, Buffa P, Di Rovasenda E, Mattioli G, Scarsi PL, Podesta $\mathrm{E}$, et al.: Treatment of vesico-ureteric reflux in children with neuropathic bladder: a comparison of surgical and endoscopic correction. J Pediatr Surg. 1999; 34: 1836-8.

12. Barroso U Jr, Jednak R, Barthold JS, González R: Outcome of ureteral reimplantation in children with the urge syndrome. $J$ Urol. 2001; 166: 1031-5.

13. Callaghan K, Gray E, Caldamone A, Ellsworth P: Factors involved in parental decision making for surgical correction of vesicoureteral reflux. J Urol. 2008; 180: 701-5; discussion 705-6.

14. Läckgren G, Wåhlin N, Sköldenberg E, Stenberg A: Longterm followup of children treated with dextranomer/ hyaluronic acid copolymer for vesicoureteral reflux. J Urol. 2001; 166: 1887-92.

15. Oswald J, Riccabona M, Lusuardi L, Bartsch G, Radmayr C: Prospective comparison and 1-year follow-up of a single endoscopic subureteral polydimethylsiloxane versus dextranomer/hyaluronic acid copolymer injection for treatment of vesicoureteral reflux in children. Urology. 2002; 60: 894-7; discussion 898. 
16. Lee EK, Gatti JM, Demarco RT, Murphy JP: Long-term followup of dextranomer/hyaluronic acid injection for vesicoureteral reflux: late failure warrants continued followup. J Urol. 2009; 181: 1869-74; discussion 1874-5.

17. Brandström P, Esbjörner E, Herthelius M, Swerkersson S, Jodal U, Hansson S: The Swedish reflux trial in children: III. Urinary tract infection pattern. J Urol. 2010; 184: 286-91.

18. Lavine MA, Siddiq FM, Cahn DJ, Caesar RE, Koyle MA, Caldamone AA: Vesicoureteral reflux after ureteroneocystostomy: indications for postoperative voiding cystography. Tech Urol. 2001; 7: 50-4.

19. Bomalaski MD, Ritchey ML, Bloom DA: What imaging studies are necessary to determine outcome after ureteroneocystostomy? J Urol. 1997; 158: 1226-8.

20. Barrieras D, Lapointe S, Reddy PP, Williot P, McLorie GA, Bigli $\mathrm{D}$, et al:: Are postoperative studies justified after extravescial ureteral reimplantation? J Urol. 2000; 164: 1064-6.

21. Chertin B, Prosolovich K, Aharon S, Nativ 0, Halachmi S: Surgical Reimplantation for the Correction of Vesicoureteral Reflux following Failed Endoscopic Injection. Adv Urol. 2011; 2011: 352716 .

22. Moreira-Pinto J, Osório A, Pereira J, Sousa C, de Castro JL, Réis A: Ureteroneocystostomy after failed dextranomer/hyaluronic acid copolymer injection for vesicoureteral reflux treatment. J Pediatr Urol. 2013; 9: 665-9.

23. Whittam BM, Thomasch JR, Makari JH, Tanaka ST, Thomas JC, Pope JC 4th, et al.: Febrile urinary tract infection after ureteroneocystostomy: a contemporary assessment at a single institution. J Urol. 2010; 183: 688-92.

24. Beetz R, Mannhardt W, Fisch M, Stein R, Thüroff JW: Long-term followup of 158 young adults surgically treated for vesicoureteral reflux in childhood: the ongoing risk of urinary tract infections. J Urol. 2002; 168: 704-7; discussion 707.

25. Dwyer ME, Husmann DA, Rathbun SR, Weight CJ, Kramer SA: Febrile urinary tract infections after ureteroneocystostomy and subureteral injection of dextranomer/hyaluronic acid for vesicoureteral reflux--do choice of procedure and success matter? J Urol. 2013; 189: 275-82.

26. Yeoh JS, Greenfield SP, Adal AY, Williot P: The incidence of urinary tract infection after open anti-reflux surgery for primary vesicoureteral reflux: early and long-term follow up. J Pediatr Urol. 2013; 9: 503-8.

27. Nelson CP, Hubert KC, Kokorowski PJ, Huang L, Prasad MM, Rosoklija I, et al.: Long-term incidence of urinary tract infection after ureteral reimplantation for primary vesicoureteral reflux. J Pediatr Urol. 2013; 9: 92-8.

28. Duong DT, Parekh DJ, Pope JC 4th, Adams MC, Brock JW 3rd: Ureteroneocystostomy without urethral catheterization shortens hospital stay without compromising postoperative success. J Urol. 2003; 170: 1570-3; discussion 1573.

29. Miller OF, Bloom TL, Smith LJ, McAleer IM, Kaplan GW, Kolon TF: Early hospital discharge for intravesical ureteroneocystostomy. J Urol. 2002; 167: 2556-9.
30. Ashley R, Vandersteen D: Outcome analysis of miniureteroneocystostomy versus dextranomer/hyaluronic acid copolymer injection for unilateral vesicoureteral reflux. J Urol. 2008; 180: 1611-3; discussion 1614.

31. Chen HW, Yuan SS, Lin CJ: Ureteral reimplantation for vesicoureteral reflux: comparison of minimally invasive extravesical with transvesical and conventional extravesical techniques. Urology. 2004; 63: 364-7; discussion 367-8.

32. McAchran SE, Palmer JS: Bilateral extravesical ureteral reimplantation in toilet trained children: Is 1-day hospitalization without urinary retention possible? J Urol. 2005; 174: 1991-3; discussion 1993.

33. Farnham SB, Adams MC, Brock JW 3rd, Pope JC 4th: Pediatric urological causes of hypertension. J Urol. 2005; 173: 697-704.

34. Köhler J, Tencer J, Thysell H, Forsberg L: Vesicoureteral reflux diagnosed in adulthood. Incidence of urinary tract infections, hypertension, proteinuria, back pain and renal calculi. Nephrol Dial Transplant. 1997; 12: 2580-7.

35. Bakkaloglu SA, Ekim M, Sever L, Noyan A, Aksu N, Akman $S$, et al.: Chronic peritoneal dialysis in Turkish children: a multicenter study. Pediatr Nephrol. 2005; 20: 644-51.

36. North American Pediatric Renal Trials and Collaborative Studies. NAPRTCS 2010 Annual Transplant Report. [Accessed in April, 2013]. Available at: https://web.emmes.com/study/ ped/annlrept/2010_Report.pdf

37. Ardissino G, Avolio L, Dacco V, Testa S, Marra G, Viganò S, et al.: Long-term outcome of vesicoureteral reflux associated chronic renal failure in children. Data from the ItalKid Project. J Urol. 2004; 172: 305-10.

38. Esbjörner E, Berg U, Hansson S: Epidemiology of chronic renal failure in children: a report from Sweden 1986-1994. Swedish Pediatric Nephrology Association. Pediatr Nephrol. 1997; 11: 438-42.

39. Coulthard MG, Vernon SJ, Lambert HJ, Matthews JN: A nurse led education and direct access service for the management of urinary tract infections in children: prospective controlled trial. BMJ. 2003; 327: 656.

40. Cendron M: Reflux nephropathy. J Pediatr Urol. 2008; 4: 41421. Erratum in: J Pediatr Urol. 2009; 5: 75. 